\title{
Opioid Use Among Those Who Have Criminal Justice Experience: Harm Reduction Strategies to Lessen HIV Risk
}

\author{
Lauren Brinkley-Rubinstein ${ }^{1,2} \cdot$ David Cloud $^{3,4} \cdot$ Ernest Drucker $^{5} \cdot$ Nickolas Zaller $^{6}$
}

Published online: 11 May 2018

\begin{abstract}
Purpose of Review We reviewed the HIV and opioid literature relevant to harm reduction strategies for those with criminal justice experience.

Recent Findings Opioid use in the United States has risen at an alarming rate recently. This has led to increased numbers of people who inject drugs, placing new populations at risk for HIV, including those who have criminal justice experience. In recent years, there has been a gradual decrease in the number of individuals under the supervision of the criminal justice system. However, concurrently, there has been a rise in the number of individuals incarcerated in jails in rural counties that are at the center of the current opioid epidemic.

Summary We provide a number of harm reduction strategies that could be implemented in correctional settings such as access and linkage to medication-assisted treatment, connection to syringe exchange programs and safe injection facilities (where available), and the repackaging of pre-exposure prophylaxis as a harm reduction tool.
\end{abstract}

Keywords Harm reduction $\cdot$ HIV $\cdot$ Opioid use $\cdot$ Criminal justice experience $\cdot$ Safe injection facilities $\cdot$ Syringe exchange programs

\section{Introduction}

The United States (US) criminal justice (CJ) system is the largest in the world, with a greater number of individuals incarcerated or under surveillance than any other nation [1]. The CJ system includes prisons that, in general, house individuals who have sentences that are greater than one year in length; jails that include pre-trial detainees or individuals who

This article is part of the Topical Collection on The Global Epidemic

Lauren Brinkley-Rubinstein

Lauren_Brinkley@med.unc.edu

1 Department of Social Medicine, University of North Carolina, Chapel Hill, NC, USA

2 Center for Health Equity Research, University of North Carolina, Chapel Hill, NC, USA

3 Vera Institute of Justice, New York, NY, USA

4 Department of Behavioral Sciences and Health Education, Emory University, Atlanta, GA, USA

5 College of Public Health, New York University, New York, NY, USA

6 Fay W. Boozman College of Public Health, University of Arkansas for Medical Sciences, Little Rock, AR, USA are typically serving sentences less than one year in length; and community supervision which includes people who are on probation or parole. A little over 6.7 million individuals or one in 37 adults was involved in the criminal justice system at year-end 2015 [1]. In recent years, there has been a gradual decrease in the number of individuals involved in the CJ system. However, concurrently, there has been a rise in the number of individuals incarcerated in jails in rural counties that are at the center of the current opioid epidemic [2].

Opioid use in the US has risen at an alarming rate in recent years. This epidemic of opioid misuse and abuse has led to increased numbers of people who inject drugs (PWID), placing new populations at increased risk for HIV [3]. Average rates of heroin use increased from 1.6 per 1000 persons over the age of 12 in 2002 to 2004 to 2.6 in 2011 to 2013 [4]. In addition, this increase in heroin use is associated with a corresponding rise in opioid-related overdose deaths. Those who have CJ experience have a higher incidence of both injection drug use (IDU) and HIV. Individuals who are CJ involved have a rate of HIV that is three times higher than the general population and more than half of all people who are incarcerated meet the diagnostic criteria for substance use disorder $[5,6]$. This is, due, in large part, to the fact that $13 \%$ of all arrests are due to drug-related crime. 
The number of individuals with opioid use disorder (OUD) is also exaggerated among those who are incarcerated [6]. Just over $23 \%$ of state prisoners report ever using heroin or other opiates, and $13 \%$ report regular use prior to incarceration [6]. In addition, people who have recently been incarcerated are at extreme risk of overdose during community re-entry [7, 8]. A recent study investigating all causes of mortality of people who were formerly incarcerated in Washington state found that overdose was the number one cause of death [8].

After release, individuals are also at increased risk of HIV transmission and contraction, as many HIV-negative individuals return to substance use in the community [9]. Research has shown that among people who inject drugs, incarceration impacts post-release HIV risk behaviors, including the sharing of used needles [10]. For those who are HIV positive, incarceration can result in HIV treatment disruption and nonadherence to antiretroviral medications [11-13]. In fact, a recent systematic review of HIV care continuum among those with criminal justice experience demonstrated that rates of viral suppression are even worse post-incarceration than before arrest [14].

However, jails and prisons have been slow to embrace harm reduction strategies. The remainder of this paper will, thus, focus on harm reduction techniques that can be deployed in CJ settings to lessen the risk of HIV transmission and contraction targeted toward opioid users.

\section{Harm Reduction Strategies for Opioid Users with Current or Recent Incarceration}

Much of the HIV harm reduction efforts among people who inject drugs have focused primarily on provision of and linkage to medication-assisted treatment (MAT), syringe exchange programs (SEPs) and related community services that often include overdose prevention, and, in a more limited capacity (in terms of geographic distribution), safe injection facilities (SIFs). In addition, herein, we propose including preexposure prophylaxis (PrEP) as a tool of harm reduction among injection drug users.

\section{Screening for Opioid Use Disorder and Risky Injecting Behaviors}

Screening and assessment tools have been developed to specifically identify those who have OUD in correctional settings. This is a necessary and crucial step in addressing OUD and subsequent HIV risk among those who are incarcerated. However, few estimates of OUD disorder among those involved in the CJ system exist mainly due to the fact that screening for OUD is not a routine practice in most correctional facilities. We recommend the inclusion of an OUD screening tool such as the Rapid Opioid Dependence Screen [15] or the Texas Christian University (TCU) drug screenopioid supplement [16] be used as a part of the intake process in concert with mandated screening tools and HIV risk assessments.

\section{Medication-Assisted Treatment as HIV Prevention}

MAT has been extensively studied over the past four decades as an effective treatment of OUD. Overall, MAT has been shown to reduce drug use, re-incarceration, and overdose; and increase continuous engagement in long-term treatment among CJ-involved individuals [17-22]. Currently, there are three medications approved by the US Food and Drug Administration (FDA) to treat OUD: the opioid agonist methadone, the opioid partial agonist buprenorphine, and the opioid antagonist naltrexone, which has also been developed in a depot, delayed release formulation for intramuscular injection.

MAT should be deployed in concert with HIV prevention and treatment adherence strategies as recent research has demonstrated that MAT, when delivered with HIV interventions, has been shown to be most effective. For instance, for both criminal justice- and non-criminal justice-involved populations, naltrexone not only effectively lowers rates of opioid use and heavy alcohol consumption but also improves rates of ART adherence in the community [23-29]. Despite the effectiveness of MAT in treating OUD both during incarceration and post-release, most correctional facilities in the US still do not provide access to these medications. We recommend more robust programs that provide MAT in concert with other HIV prevention strategies.

\section{Repackaging Pre-exposure Prophylaxis as Harm Reduction}

One of the HIV prevention strategies that could be combined with MAT programs is pre-exposure prophylaxis (PrEP). PrEP is a once daily medication (emtricitabine/tenofovir disoproxil fumurate FTC/TDF) that has demonstrated efficacy in preventing HIV among at risk groups including PWID [30, 31]. In a randomized, double-blind, placebo-controlled trial that included 17 drug treatment clinics in Bangkok, Thailand, there was a $48.9 \%$ reduction in HIV incidence with use of PrEP [31]. However, while PrEP has demonstrated efficacy among PWID, in general, less is known about barriers and facilitators of PrEP uptake and adherence among PWID who have been recently incarcerated. Additionally, important opportunities exist to gauge the possible "de-medicalization of PrEP" to increase and ease access to this prevention method and branding of PrEP, similar to syringe exchange, as a harm 
reduction tool. This follows the Centers for Disease Control and Prevention's recommendations that PrEP be provided to PWID as part of a comprehensive package of prevention services [32]. Best practices for PrEP provision or linkage for PWID should be investigated, but could take one of the following forms: (1) providing a PrEP prescription just prior to discharge with linkage to a community PrEP provider, (2) solely linking to a PrEP provider during discharge planning [33].

\section{Syringe Exchange Program Linkage}

One of the pillars of harm reduction has been SEPs which can be important portals to accessing services for PWID, including overdose prevention assistance. SEPs provide a wide variety of services including condom distribution, referrals for substance use treatment, HIV and hepatitis $\mathrm{C}$ virus counseling and testing, and overdose training and prevention [34]. A large body of evidence has clearly demonstrated that SEPs substantially reduce the risk for HIV transmission among PWID [34]. While few studies have explicitly looked at the subset of PWID who report criminal justice involvement, SEPs can provide a range of important services to individuals with OUD upon release from incarceration or who are on community supervision. Linkage efforts could include access to an educational program that introduces the concept of harm reduction and syringe exchange. During this program, individuals could be enrolled in syringe exchange making easier their ability to access clean needles immediately upon release. This is the model that the North Carolina Harm Reduction Coalition is using in jails and prisons across the state of North Carolina (see: www.nchrc.org).

\section{Access to Safe Injection Facilities}

Another important harm reduction strategy that has been gaining increasing attention in recent years is safe injection facilities (SIFs). These facilities provide PWID with sterile injecting equipment and a safe space in which to inject under the supervision of nurses and/or other healthcare personnel. SIFs have been well studied and have been shown to reduce overdose mortality [35] and injection-related injuries [35-37]. Importantly, these facilities have not been associated with increases in the number of PWID [37], increased rates of relapse [38], increases in publicly discarded injection equipment [39], or increases in drug-related crime [40]. In addition, SIFs have been shown to increase utilization of detox services [40,41] and substance use treatment [41-43].

\section{Conclusion}

As the number of opioid users in the US continues to rise, multipronged harm reduction strategies must be deployed with diverse groups of people at risk. Individuals who have current or recent $\mathrm{CJ}$ involvement are a key population group that is at increased risk of HIV transmission and infection. To lessen this risk, we suggest expansion of MAT programs in correctional settings that are implemented in concert with HIV prevention efforts. In addition, opioid users involved in the CJ system should be linked to SIFs and SEPs prior to release. Finally, PrEP should be offered as a tool of harm reduction alongside syringe exchange, MAT, and SIF linkage.

\section{Compliance with Ethical Standards}

Conflict of Interest The authors declare that they have no competing interests.

Human and Animal Rights and Informed Consent This article does not contain any studies with human or animal subjects performed by any of the authors.

\section{References}

1. Kaeble D, Glaze L. Correctional populations in the United States, 2015. Washington, DC: Bureau of Justice Statistics; 2016.

2. Kang-Brown J, Subramanian R. Out of sight: The growth of rural jails in America. New York, NY: Vera Institute of Justice; 2017.

3. Centers for Disease Control and Prevention. Diagnoses of HIV Infection in the United States and Dependent Areas, 2015. HIV Surveillance Report (27).

4. Jones CM, Logan J, Gladden RM, Bohm MK. Vital signs: demographic and substance use trends among heroin users-United States, 2002-2013. MMWR. 2015;64(26):719-25.

5. Spaulding AC, Seals RM, Page MJ, Brzozowski AK, Rhodes W, Hammett TM. HIV/AIDS among inmates of and releases from US correctional facilities, 2006: declining share of epidemic but persistent public health opportunity. Plos One. 2009;4:e7558.

6. Mumola CJ, Karberg JC. Drug use and dependence, state and federal prisoners, 2004. Washington, DC: Bureau of Justice Statistics; 2006.

7. Binswanger IA, Stern MF, Deyo RA, Heagerty PJ, Cheadle A, Elmore JG, et al. Release from prison - a high risk of death for former inmates. N Engl J Med. 2007;356(2):157-65.

8. Binswanger IA, Blatchford PJ, Mueller SR, Stern MF. Mortality after prison release: Opioid overdose and other causes of death, risk factors, and time trends from 1999 to 2009. Ann Intern Med. 2013;159(5):592-600.

9. Ramaswamy M, Freudenberg N. Sex partnerships, health, and social risks of young men leaving jail: analyzing data from a randomized controlled trial. BMC Public Health. 2010;10(1):689-97. PMCID: PMC2988744

10. Milloy MJ, Buxton J, Wood E, Li K, Julio SG, Kerr T. Elevated HIV risk behaviour among recently incarcerated injection drug users in a Canadian setting: a longitudinal analysis. BMC Public Health. 2009;9:156. 
11. Westergaard RP, Kirk GD, Richesson DR, Galai N, Mehta SH. Incarceration predicts virologic failure for HIV-infected injection drug users receiving antiretroviral therapy. Clin Infect Dis. 2011;53(7):725-31.

12. Milloy MJ, Kerr T, Buxton J, Rhodes T, Guillemi S, Hogg R, et al. Dose-response effect of incarceration events on nonadherence to HIV antiretroviral therapy among injection drug users. J Infect Dis. 2011;203(9):1215-21.

13. Meyer JP, Cepeda J, Wu J, Trestman RL, Altice FL, Springer SA. Optimization of human immunodeficiency virus treatment during incarceration: viral suppression at the prison gate. JAMA Intern Med. 2014;174(5):721-9.

14. Iroh PA, Mayo H, Nijhawan AE. The HIV care Cascade before, during, and after incarceration: a systematic review and data synthesis. Am J Public Health. 2015;105:e5-e16.

15. Wickersham JA, Azar MM, Cannon CM, Altice FL, Springer SA. Validation of a brief measure of opioid dependence: the rapid opioid dependence screen (RODS). J Correct Health Care. 2015;21(1):12-26.

16. Texas Christian University Institute of Behavioral Research. TCU drug screen 5 opioid supplement. Fort Worth, TX: TCU; 2017.

17. Perry AE, Neilson M, Martyn-St James M, Glanville JM, Woodhouse R, Godfrey C, Hewitt C. Pharmacological interventions for drug-using offenders. Cochrane Database Syst Rev 2015, Issue 6. Art. No.: CD010862.

18. McKenzie M, Zaller N, Dickman SL, Green TC, Parihk A, Friedmann PD, et al. A randomized trial of methadone initiation prior to release from incarceration. Subst Abuse. 2012;33:19-29.

19. Gordon MS, Kinlock TW, Schwartz RP, O'Grady KE. A randomized clinical trial of methadone maintenance for prisoners: findings at 6 months post-release. Addiction. 2008;103:1333-42.

20. Kinlock TW, Gordon MS, Schwartz RP, O'Grady K, Fitzgerald TT, Wilson M. A randomized clinical trial of methadone maintenance for prisoners: results at 1-month post-release. Drug Alcohol Depend. 2007;91:220-7.

21. Brinkley-Rubinstein L, McKenzie M, Macmadu A, Zaller N, Larney S, Dauria E, Rich J. A randomized, open label trial of methadone continuation versus forced withdrawal in a combined US prison and jail: findings at 12 -months post-release. Drug Alcohol Depend. 2018.

22. Green TC, Clarke J, Brinkley-Rubinstein L, Marshall BD, Alexander-Scott N, Boss R, Rich JD. Postincarceration fatal overdoses after implementing medications for addiction treatment in a statewide correctional system. JAMA Psychiat. 2018;75(4):405-7.

23. Springer SA, Di Paola A, Azar MM, Barbour R, Krishnan A, Altice FL. Extended-release naltrexone reduces alcohol consumption among released prisoners with HIV disease as they transition to the community. Drug Alcohol Depend. 2017;174:158-70.

24. Korthuis PT, Lum PJ, Vergara-Rodriguez P, Ahamad K, Wood E, Kunkel LE, et al. Feasibility and safety of extended-release naltrexone treatment of opioid and alcohol use disorder in HIV clinics: a pilot/feasibility randomized trial. Addiction. 2017;112(6):1036-44.

25. Nosyk B, Min JE, Colley G, Lima VD, Yip B, Milloy MJS, et al. The causal effect of opioid substitution treatment on HAART medication refill adherence. AIDS. 2015;29(8):965-73.

26. Springer SA, Azar MM, Altice FL. HIV, alcohol dependence, and the criminal justice system: a review and call for evidence-based treatment for released prisoners. Am J Drug Alcohol Abuse. 2011;37(1):12-21.

27. Altice FL, Bruce RD, Lucas GM, Lum PJ, Korthuis PT, Flanigan TP, et al. HIV treatment outcomes among HIV-infected, opioiddependent patients receiving buprenorphine/naloxone treatment within HIV clinical care settings: results from a multisite study. J Acquir Immune Defic Syndr. 2011;56(Suppl 1):S22-32.
28. Springer S, Barbour R, Azar M, Alice FL, Di Paola A. Results of a double blind placebo controlled randomized trial of extendedrelease naltrexone among HIV+ inmates with alcohol use disorders. The College on Problems of Drug Dependence; 2017 June 17-22; Montréal, Canada; 2017.

29. Springer S, Barbour R, Azar M, et al. Results of a double blind placebo-controlled randomized trial of extended-release naltrexone among HIV+ inmates with opioid dependence The College on Problems of Drug Dependence; 2017 June 17-22; Montréal, Canada; 2017.

30. Thigpen MC, Kebaabetswe PM, Paxton LA, Smith DK, Rose CE, Segolodi TM, et al. Antiretroviral preexposure prophylaxis for heterosexual HIV transmission in Botswana. N Engl J Med. 2012;367(5):423-34.

31. Choopanya K, Martin M, Suntharasamai P, Sangkum U, Mock PA, Leethochawalit M, et al. Antiretroviral prophylaxis for HIV infection in injecting drug users in Bangkok, Thailand (the Bangkok Tenofovir Study): a randomized, double-blind, placebo-controlled phase 3 trial. Lancet. 2013;381:2083-90.

32. Centers for Disease Control and Prevention (CDC). Pre-exposure prophylaxis for the prevention of HIV infection in the United States-2014: A clinical practice guideline. Atlanta, GA: CDC; 2014.

33. Brinkley-Rubinstein L, Dauria E, Tolou-Shams M, Christopoulos $\mathrm{K}$, Chan PA, Beckwith CG, et al. The path to implementation of HIV pre-exposure prophylaxis for people involved in criminal justice systems. Curr. HIV/AIDS Rep. 2018;15(2):93-5.

34. Des Jarlais DC, McKnight C, Goldblatt C, Purchase D. Doing harm reduction better: syringe exchange in the United States. Addiction. 2009; 104:1441-6.

35. Marshall BD, Milloy MJ, Wood E, Montaner JS, Kerr T. Reduction in over- dose mortality after the opening of North America's first medically supervised safer injecting facility: a retrospective population-based study. Lancet. 2011;377(9775):1429-37.

36. Kerr T, Small W, Moore D, Wood E. A micro-environmental intervention to reduce the harms associated with drug-related overdose: evidence from the evaluation of Vancouver's safer injection facility. Int J Drug Policy. 2007;18(1):37-45.

37. Milloy MJ, Kerr T, Mathias R, Zhang R, Montaner JS, Tyndall M, et al. Non-fatal overdose among a cohort of active injection drug users recruited from a supervised injection facility. Am J Drug Alcohol Abuse. 2008;34(4):499-509.

38. Wood E, Tyndall MW, Lai C, Montaner JS, Kerr T. Impact of a medically supervised safer injecting facility on drug dealing and other drug-related crime. Subst Abuse Treat Prev Policy. 2006;1:13.

39. Kerr T, Stoltz JA, Tyndall M, Li K, Zhang R, Montaner J, et al. Impact of a medically supervised safer injection facility on community drug use patterns: a before and after study. BMJ. 2006;332(7535):220-2.

40. Wood E, Kerr T, Montaner JS, Strathdee SA, Wodak A, Hankins CA, et al. Rationale for evaluating North America's first medically supervised safer- injecting facility. Lancet Infect Dis. 2004;4(5): $301-6$.

41. Wood E, Tyndall MW, Zhang R, Montaner JS, Kerr T. Rate of detoxification service use and its impact among a cohort of supervised injecting facility users. Addiction. 2007;102(6):916-9. https://doi.org/10.1111/j.1360-0443.2007.01818.x.

42. DeBeck K, Kerr T, Bird L, Zhang R, Marsh D, Tyndall M, et al. Injection drug use cessation and use of North America's first medically supervised safer injecting facility. Drug Alcohol Depend. 2011;113(2-3):172-6.

43. Kimber J, Dolan K, van Beek I, Hedrich D, Zurhold H. Drug consumption facilities: an update since 2000. Drug Alcohol Rev. 2003;22(2):227-33. 